nephron

Experimental

Nephrology

and Genetics
Nephron 2019;142:51-60

DOI: $10.1159 / 000496617$
Received: December 13, 2017

Accepted after revision: December 21, 2018

Published online: February 22, 2019

\title{
Effect of Dapagliflozin Treatment on the Expression of Renal Sodium Transporters/ Channels on High-Fat Diet Diabetic Mice
}

\author{
Chao Ma ${ }^{a}$ Jeroen H.F. de Baaij ${ }^{a}$ Paul J. Millar ${ }^{c}$ Victor A. Gault ${ }^{c}$ \\ Bastiaan E. de Galan ${ }^{b}$ René J.M. Bindels ${ }^{a}$ Joost G.J. Hoenderop ${ }^{a}$ \\ ${ }^{a}$ Department of Physiology, Radboud Institute for Molecular Life Sciences, Radboud University Medical Center, \\ Nijmegen, The Netherlands; ${ }^{b}$ Internal Medicine, Radboud Institute for Molecular Life Sciences, Radboud University \\ Medical Center, Nijmegen, The Netherlands; ' SAAD Centre for Pharmacy and Diabetes, School of Biomedical \\ Sciences, University of Ulster, Coleraine, UK
}

\section{Keywords}

Dapagliflozin · Type 2 diabetes · Renal sodium transporters

\begin{abstract}
Background: Inhibition of the $\mathrm{Na}^{+} /$glucose co-transporter 2 is a new therapeutic strategy for diabetes. It is unclear how proximal loss of $\mathrm{Na}^{+}$(and glucose) affects the subsequent $\mathrm{Na}^{+}$transporters in the proximal tubule (PT), thick ascending limb of loop of Henle (TAL), distal convoluted tubule (DCT) and collecting duct (CD). Methods: Mice on a high fat diet were administered 3 doses streptozotocin 6 days prior to oral dapagliflozin administration or vehicle for 18 days. A control group of lean mice were also included. Body weight and glucose were recorded at regular intervals during treatment. Renal $\mathrm{Na}^{+}$transporters expression in nephron segments were analyzed by RT-qPCR and Western blot. Results: Dapagliflozin treatment resulted in a significant reduction in
\end{abstract}

body weight and blood glucose compared to vehicle-treated controls. mRNA results showed that $\mathrm{Na}^{+}$-hydrogen antiporter 3 (NHE3), $\mathrm{Na}^{+} /$phosphate cotransporter ( $\mathrm{NaPi}-2 \mathrm{a}$ ) and epithelial $\mathrm{Na}^{+}$channel expression was increased, Ncx1, $\mathrm{ENaC} \beta$ and $\mathrm{ENaC} \gamma$ expression declined ( $p$ all $<0.05$ ), respectively, in dapagliflozin-treated mice when compared with saline vehicle mice. $\mathrm{Na}-\mathrm{K}-2 \mathrm{Cl}$ cotransporters and $\mathrm{Na}-\mathrm{Cl}$ cotransporter mRNA expression was not affected by dapagliflozin treatment. $\mathrm{Na}^{+} / \mathrm{K}^{+}$-ATPase (Atp1b1) expression was also increased significantly by dapagliflozin treatment, but it did not affect Atp1a1 and glucose transporter 2 expression. Western blot analysis showed that NaPi-2a, NHE3 and ATP1b1 expression was upregulated in dapagliflozin-treated diabetic mice when compared with saline vehicle mice $(p<$ 0.05). Conclusion: Our findings suggest that dapagliflozin treatment augments compensatory changes in the renal PT in diabetic mice.

(c) 2019 The Author(s)

Published by S. Karger AG, Basel

\begin{tabular}{ll}
\hline KARGER & $\begin{array}{l}\text { () } 2019 \text { The Author(s) } \\
\text { Published by S. Karger AG, Basel Oparger }\end{array}$ \\
E-Mail karger@karger.com & This article is licensed under the Creative Commons Attribution- \\
www.karger.com/nef & $\begin{array}{l}\text { NonCommercial-NoDerivatives 4.0 International License (CC BY- } \\
\text { NC-ND) (http://www.karger.com/Services/OpenAccessLicense). } \\
\text { Usage and distribution for commercial purposes as well as any dis- } \\
\text { tribution of modified material requires written permission. }\end{array}$
\end{tabular}

Joost G.J. Hoenderop

Department of Physiology, Radboud Institute for Molecular Life Sciences Radboud University Medical Center

PO Box 9101, NL-6500 HB Nijmegen (The Netherlands)

E-Mail Joost.Hoenderop@ radboudumc.nl 
Type 2 diabetes mellitus is a major health problem affecting 415 million people worldwide $[1,2]$. This represents $8.3 \%$ of the adult population, with equal rates in women and men [3]. From 2012 to 2015, approximately 1.5-5.0 million deaths each year resulted from diabetes [4]. Diabetes and hypertension frequently occur together [5]. Hypertension in these patients further increases their already elevated cardiovascular risks, yet is difficult to manage. Indeed, in about half of the diabetic population, blood pressure targets are not met despite the use of multiple blood pressure lowering drugs, including diuretics [6-8].

Recently, dapagliflozin, a sodium-glucose co-transporter 2 (SGLT2) inhibitor, was introduced as a novel class of glucose-lowering agents for the treatment of type 2 diabetes. As SGLT2 is responsible for approximately $90 \%$ of the filtered glucose reabsorption in the proximal tubule (PT) segment 1 and 2 [9-11], its inhibition reduces renal glucose and sodium $\left(\mathrm{Na}^{+}\right)$reabsorption, leading to urinary glucose excretion and a reduction in blood glucose levels [12]. Therefore, dapagliflozin is an efficient novel drug to treat patients with type 2 diabetes mellitus [13-16].

Some studies have also demonstrated that SGLT2 inhibitors exhibit an impressive diuretic effect and consequent blood pressure reduction, whereas others described modest effects on volume status [17-20]. SGLT2 inhibition reduces $\mathrm{PT} \mathrm{Na}{ }^{+}$reabsorption and thereby increases the distal tubular $\mathrm{Na}^{+}$load, which inhibits the renin-angiotensin-aldosterone system activation [21]. The kidneys efficiently reabsorb $99 \%$ of filtered $\mathrm{Na}^{+}$by the combined action of (i) the PT where $60-70 \%$ is reabsorbed via $\mathrm{Na}^{+}$-hydrogen antiporter 3 (NHE3), SGLT1 and SGLT2 [22]; (ii) the thick ascending limb (TAL) of Henle's loop that is responsible for 15-25\% reabsorption via paracellular routes and $\mathrm{Na}-\mathrm{K}-2 \mathrm{Cl}$ cotransporter (NKCC2); (iii) the distal convoluted tubule (DCT) that reabsorbs $15-25 \%$ via the thiazide-sensitive $\mathrm{Na}-\mathrm{Cl}$ cotransporter (NCC) [23]; (iv) the collecting duct (CD) where the $\mathrm{ENaC}$ facilitates the reabsorption of the remaining $1-2 \%[10,24]$.

A recent study has found that treatment with an SGLT2 inhibitor increases the expression of urea transporter-A1, aquaporin-2 and NKCC2 proteins [1]. However, a systematic analysis of the compensatory mechanisms that regulate renal $\mathrm{Na}^{+}$reabsorption after SGLT2 treatment is lacking. Knowledge of which nephron segment compensates for proximal $\mathrm{Na}^{+}$loss is of great fundamental and clinical interest, as this would provide the major pharmacological target for antihypertensive treatment.
The purpose of this study was to identify the compensatory impact of proximal $\mathrm{Na}^{+}$wasting by the SGLT2 inhibitor, dapagliflozin, on renal $\mathrm{Na}^{+}$transporters in highfat diabetic mice.

\section{Materials and Methods}

\section{The Following Primary Antibodies Were Used}

NCC (Millipore, Billerica, MA, USA; \#AB3553; immunoblotting [IB] 1:2,000), and sheep anti NKCC2, IB 1:2,000 [25], $\mathrm{Na}^{+}$/ phosphate cotransporter (NaPi-2a; kind gift of Dr. Custer et al. [26]; IB 1:2,000), NHE3 (Millipore, Billerica, MA, USA; \# AB3085; IB 1:500) [27], ATP1b1 (Merck KGaA, Darmstadt, Germany; \# 05382; IB 1:500) [28]. Secondary antibodies were as follows: peroxidase conjugated goat anti-rabbit (Sigma-Aldrich; \# A4914; IB 1: 10,000); peroxidase conjugated sheep anti-mouse (Jackson ImmunoResearch Laboratories Inc., West Grove, PA, USA; \#515-035003; IB 1: 10,000).

\section{Buffers}

Lysis buffer: $150 \mathrm{~mm} \mathrm{NaCl}, 50 \mathrm{~mm}$ Tris- $\mathrm{HCl}$ (pH 7.5), $1 \mathrm{~mm}$ EDTA, 1 mM EGTA, $1 \mathrm{~mm}$ sodium-orthovanadate, $1 \%(\mathrm{v} / \mathrm{v})$ Triton X-100, $10 \mathrm{mM}$ sodium-glycerophosphate, $50 \mathrm{mM}$ sodium fluoride, $0.27 \mathrm{M}$ sucrose, $10 \mathrm{mM}$ sodium pyrophosphate, containing freshly added tablet of complete protease inhibitor cocktail (Roche, Basel, Switzerland) and $0.1 \%$ (v/v) $\beta$-mercaptoethanol. SDS-PAGE sample buffer: $5 \times 10 \%(\mathrm{w} / \mathrm{v})$ SDS, $10 \mathrm{mM} \beta$-mercaptoethanol, $50 \%$ (v/v) glycerol, $0.3 \mathrm{M}$ Tris- $\mathrm{HCl}(\mathrm{pH} 7.5), 0.05 \%$ (w/v) bromophenol blue. TBS-T (Tris-buffered saline, $0.1 \%$ [v/v] Tween 20): Tris- $\mathrm{HCl}$ (200 mM, pH 7.5), 0.15 M NaCl, and 0.2\% (v/v) Tween-20.

\section{Animal Model}

Adult Swiss male mice (Harlan, Oxon, UK) at 16 weeks of age were housed in an air-conditioned room at $22 \pm 2{ }^{\circ} \mathrm{C}$ with $12: 12 \mathrm{~h}$ light/dark cycle. Mice had free access to high-fat diet (45\% AFE Fat; Special Diet Services, Witham, UK; total energy $26.15 \mathrm{~kJ} / \mathrm{g}$ ). An additional lean group had free access to standard rodent chow (Teklad Global 18\% Protein Rodent Diet; Harlan, UK; total energy $13.0 \mathrm{~kJ} / \mathrm{g}$ ). All animals were free to access drinking water and respective diet, and no adverse effects were observed during the entire experimental study. All experiments were performed according to the Principles of Laboratory Animal Care (NIH publication no. 86-23, revised 1985) and UK Home Office Regulations (UK Animals Scientific Procedures Act 1986).

\section{Experimental Treatments}

Mice commenced high-fat diet on day -20 and remained on this diet for the duration of the study. On day -6 , streptozotocin (50 mg/ kg; i.p.; Sigma-Aldrich, Dorset, UK) freshly prepared in ice-cold 0.1 $\mathrm{M} \mathrm{Na}^{+}$citrate buffer $(\mathrm{HCl} / \mathrm{pH} 4.5)$ was administered 3 doses in total over a period of 6 days to induce diabetes. On day 0 , one group of high-fat mice $(n=8)$ commenced daily treatment with dapagliflozin (1 mg/kg; p.o.; Stratech Scientific Ltd., Suffolk, UK) for 18 days, whereas high-fat control group $(n=8)$ received saline vehicle $(0.9 \% \mathrm{w} / \mathrm{v} \mathrm{NaCl}$; p.o.) once-daily for the same time period. The volume for the oral gavage was $100 \mu \mathrm{L}$. A diagrammatic representation of the experimental design is shown in Figure 1.
Ma/de Baaij/Millar/Gault/de Galan/ Bindels/Hoenderop 
Fig. 1. Timeline for the experimental study. Group 1 (lean control): lean mice on normal diet for 38 days. Group 2 (high-fat controls): mice commenced a high fat diet on day -20 and subsequently received STZ treatment on day -6 . At day 0 , saline vehicle was administered for 18 days. Group 3 (high-fat dapagliflozin): mice commenced high fat diet on day -20 and subsequently received STZ on day -6 . At day 0, dapagliflozin was administered for 18 days. Lean, lean control mice; HFD, high fat diet treatment; DAPA, dapagliflozin-treated mice; STZ, streptozotocin-treated mice.

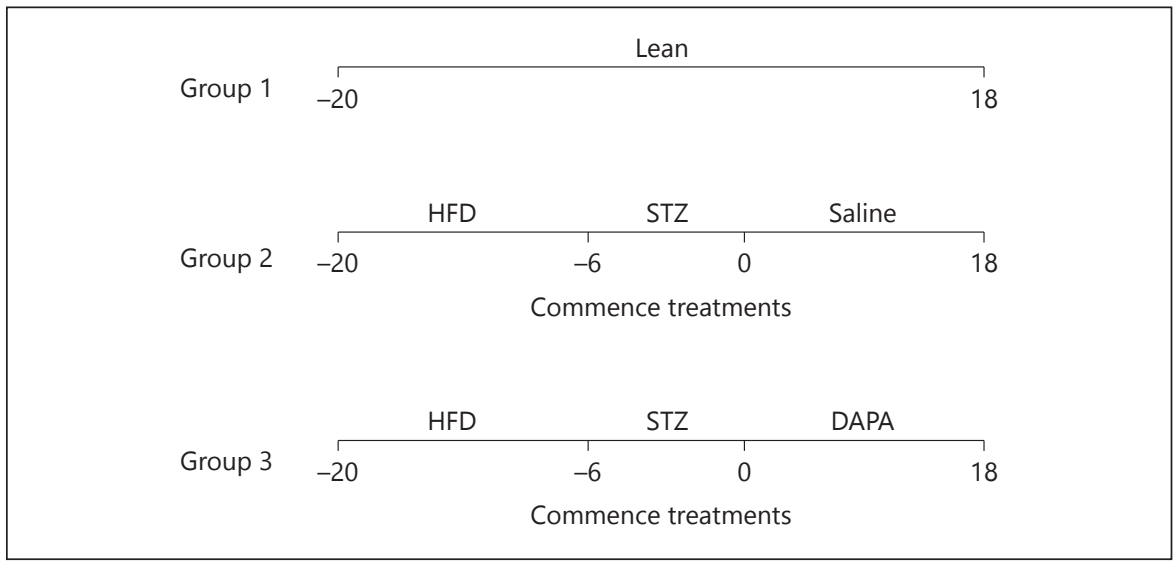

Table 1. Primer sequences used for real-time quantitative RT-PCR

\begin{tabular}{lll}
\hline Gene & Forward primer $5^{\prime}-3^{\prime}$ & Reverse primer $5^{\prime}-3^{\prime}$ \\
\hline SGLT2 & ATGGAGCAACACGTAGAGGC & ACATAGACCACAAGCCAACACC \\
SGLT1 & TCTGTAGTGGCAAGGGGAAG & ACAGGGCTTCTGTGTCTTGG \\
$N a P i-2 a$ & AGGTGAGCTCCGCCATTCCGA & CCCTGCAAAAGCCCGCCTGA \\
$N$ KCC 2 & GGCTTGATCTTTGCTTTTGC & CCATCATTGAATCGCTCTCC \\
$N C C$ & CTTCGGCCACTGGCATTCTG & GATGGCAAGGTAGGAGATGG \\
$N c x 1$ & TCCCTACAAAACTATTGAAGGCACA & TTTCTCATACTCCTCGTCATCGATT \\
$E N a C \alpha$ & GCTCAACCTTGACCTAGACCT & GCGGTGGAACTCGATCAGT \\
$E N a C \beta$ & GTCATCGGAACTTCACGCCTAT & TCCTCCTGACCGATGTCCAG \\
$E N a C \gamma$ & TGACCTGCTTCTTCGATGGG & TTGCAGACCATACTCACTGCC \\
$A t p 1 a 1$ & GGGGTTGGACGAGACAAGTAT & CGGCTCAAATCTGTTCCGTAT \\
Atp $1 b 1$ & ATCTCCTTCCGTCCTAATGACC & CTCGAAAATCATGTCGTCCTTCT \\
Glut2 & AGAAGACAAGATCACCGGAACC & TCACACCGATGTCATAGCCG \\
GAPDH & TAACATCAAATGGGGTGAGG & GGTTCACACCCATCACAAAC \\
\hline
\end{tabular}

SGLT2, sodium-glucose co-transporter 2; NaPi-2a, Na+/phosphate cotransporter; NKCC2, Na-K-2Cl cotransporter; NCC, Na-Cl cotransporter; $\mathrm{ENaCa}$, epithelial Na+ channel; Glut2, glucose transporter 2; GAPDH, glyceraldehyde 3-phosphate dehydrogenase.

Quantitative Analyses of Gene Expression

At study termination, total RNA was extracted from mouse kidney tissues with Trizol (Invitrogen, Carlsbad, CA, USA) according to the manufacturer's protocol. Subsequently, mouse RNA samples were subjected to DNase treatment to prevent genomic DNA contamination and the reverse transcriptase reaction was subsequently performed to synthesize cDNA [29]. mRNA levels of the target genes were determined by relative RT-qPCR following the MIQE guidelines 20 with a CFX96TM Real-Time PCR Detection System (Bio-Rad Laboratories, Hercules, CA, USA) using iQTM SYBR Green Supermix (Bio Rad) detection of single PCR product accumulation. Each group had 8 kidneys and RT-qPCR experiments were commenced in triplicate. Primers for SGLT2, SGLT1, NHE3, NaPi-2a, NKCC2, NCC, Ncx1, ENaC $(\alpha, \beta, \gamma)$ were purchased from Biolegio BV (Nijmegen, Netherlands). In this study, gene expression levels were normalized to the expression levels of the standard speciesspecific reference genes glyceraldehyde 3-phosphate dehydroge- nase. Here, the relative mRNA expression was analyzed using the Livak method $\left(2^{-\Delta \Delta C t}\right)$. Primer sequences are shown in Table 1.

\section{Protein Isolation}

Kidney tissues were isolated from mice and homogenized in ice cold lysis buffer. The kidney lysates were clarified by centrifugation at $4{ }^{\circ} \mathrm{C}$ for $15 \mathrm{~min}$ at $16,110 \mathrm{~g}$ and supernatants stored at $-80^{\circ} \mathrm{C}$. Bradford method was used to determine protein concentrations according to the manufacturer's protocol (Bio-Rad).

\section{Immunoblotting}

Lysates $(20 \mu \mathrm{g})$ in SDS sample buffer were added to electrophoresis on Criterion TGX precast gels (Bio-Rad) and then the gels were transferred to PVDF membranes. The membranes were blocked in TBS-T containing 5\% (w/v) non-fat dry milk (NFDM) for $1 \mathrm{~h}$ at room temperature. Subsequently, they were immunoblotted at $4{ }^{\circ} \mathrm{C}$ with primary antibody overnight. Next day, the blots 
Table 2. Effects of high fat feeding and dapagliflozin on body weight and blood glucose

\begin{tabular}{|c|c|c|c|c|c|c|}
\hline \multirow[t]{2}{*}{ Parameter } & \multicolumn{2}{|c|}{ Lean $(n=8)$} & \multicolumn{2}{|c|}{$\mathrm{HF}+$ saline $(n=8)$} & \multicolumn{2}{|c|}{$\mathrm{HF}+\mathrm{DAPA}(n=8)$} \\
\hline & 0 day & 18 days & 0 day & 18 days & 0 day & 18 days \\
\hline Body weight, g & $37.6 \pm 5.2$ & $36 \pm 2.3$ & $45.7 \pm 4.2$ & $50.2 \pm 4.3^{\mathrm{a}}$ & $43.5 \pm 5.7$ & $37.6 \pm 5.2^{\mathrm{b}}$ \\
\hline Blood glucose, mM & $5.2 \pm 0.9$ & $5.8 \pm 0.4$ & $18.5 \pm 3.7$ & $22.3 \pm 4.1^{\mathrm{a}}$ & $17.6 \pm 1.7$ & $7.6 \pm 2.1^{b}$ \\
\hline
\end{tabular}

Data is mean \pm SEM.

a $p<0.05$ vs. lean.

${ }^{\mathrm{b}} p<0.05$ vs. HF + saline.

Lean, lean control mice; HF + saline, saline vehicle diabetic mice; DAPA, dapagliflozin ( $1 \mathrm{mg} / \mathrm{kg})$ treated diabetic mice. 0 day, day 0 , saline vehicle and DAPA were administered; 18 days, day 18, saline vehicle and DAPA were administered for 18 days.

were washed with TBS-T to remove unbound primary antibody and incubated with horseradish peroxidase conjugated secondary antibodies for $1 \mathrm{~h}$ at room temperature. After subsequent washes, the protein was visualized with chemiluminescent reagent (SuperSignal West femto/pico; Thermo Scientific, Waltham, MA, USA) and processed with the Bio-Rad ChemiDoc XRS. The NaPi-2a, NaPi-2c, NHE3, NCC, NKCC2 and ATP1b1 bands on the immunoblots were quantified with gel analyzer.

Statistical Analyses

Data is shown as means \pm SEM. One-way ANOVA followed by Scheffe's test was used to examine the differences between groups. A $p$ value $<0.05$ was considered statistically significant.

\section{Results}

\section{Effects of High-Fat Feeding and Dapagliflozin on Body} Weight and Blood Glucose

Mice receiving the high-fat diet increased in body weight from day -20 to day 0 more than those receiving normal chow $(p<0.05)$. From day 0 to 18 , high-fat control mice displayed a further modest increase in body weight $(p<0.05)$, whereas mice treated with dapagliflozin exhibited a significant reduction in body weight $(p<0.05)$. Body weights of lean mice did not differ during the study. High-fat control mice displayed increased blood glucose concentrations from day 0 to $18(p<0.05)$. In contrast, high-fat mice treated with dapagliflozin exhibited a marked reduction in blood glucose $(p<0.05)$. Glucose concentrations were unchanged in lean mice. Results are shown in Table 2.

\section{The Effect of Dapagliflozin on $\mathrm{Na}^{+}$Transporter}

Expression in the PT

RT-qPCR was performed to analyze the renal expression of SGLT1, SGLT2, NHE3, NaPi-2a in the dapagliflozin-treated and control group mice. NHE3 and $\mathrm{NaPi}-2 \mathrm{a}$ gene expression was increased significantly by 33 and $34 \%$ ( $p<0.05$ each), respectively, in the dapagliflozin-treated mice compared to high-fat control group (Fig. 2c, d). In contrast, there were no significant differences in the expression of SGLT2 and SGLT1 $(p>0.2)$ between the dapagliflozin-treated group and the vehicle-control group (Fig. 2a, b). Protein expression level of NaPi-2a and NHE3 was further investigated by Western blot analysis (Fig. 2e). The expression of NaPi-2a and NHE3 was increased by 55 and $139 \%$ in the dapagliflozin-treatment group when compared with saline vehicle diabetic mice $(p<0.05$; Fig. 2f, g).

\section{The Effect of Dapagliflozin on $\mathrm{Na}^{+}$Transporter}

Expression in TAL and DCT

In order to study the effect of dapagliflozin on the expression of the $\mathrm{Na}^{+}$transporters in the TAL and DCT, the expression of NKCC2, NCC and Ncx1 was analyzed by RT-qPCR. The expression of NKCC 2 and NCC tended to increase by 23 and $17 \%$, respectively, in the dapagliflozin treatment group (Fig. 3a, b). However, these changes did not reach statistical significance. The expression of $\mathrm{Ncx} 1$ decreased by $27 \%$ in the dapagliflozin treatment group when compared with that of the vehicle-control group ( $p<0.05$; Fig. 3c). Dapagliflozin treatment did not alter NCC and NKCC2 protein abundance when compared with saline vehicle diabetic mice (Fig. 3e, f).

\section{The Effect of Dapagliflozin on $\mathrm{Na}^{+}$Transporter/}

Channel Expression in the $C D$

To further investigate the effect of proximal $\mathrm{Na}^{+}$loss on the $\mathrm{CD}$, we tested the expression of the $\mathrm{ENaC}(\alpha, \beta$ and $\gamma$ ) by RT-qPCR. Dapagliflozin treatment increased the expression of epithelial $\mathrm{Na}^{+}$channel $(\mathrm{ENaC} \alpha)$ by $29 \%$ 
Fig. 2. Effect of dapagliflozin on the expression of the sodium transporters in the PT. a-d Quantitative RT-PCR analyses for the expression of SGLT2, SGLT1, NHE3 and $\mathrm{NaPi}-2 a$ in the PT. e, f Immunoblot analysis of NaPi-2a $(\sim 70 \mathrm{kDa}), \mathrm{NHE} 3(\sim 93 \mathrm{kDa})$ in mice fed the indicated diet. $\mathbf{g}$, $\mathbf{h}$ Histograms for NaPi-2a, NHE3 Western blot results and normalized for $\beta$-actin expression. ${ }^{*} p<0.05$. Lean, lean control mice; $\mathrm{HF}$, saline vehicle mice; DAPA, dapagliflozin-treated mice. NHE3, $\mathrm{Na}^{+}$-hydrogen antiporter 3; NaPi-2a, $\mathrm{Na}^{+} /$phosphate cotransporter.

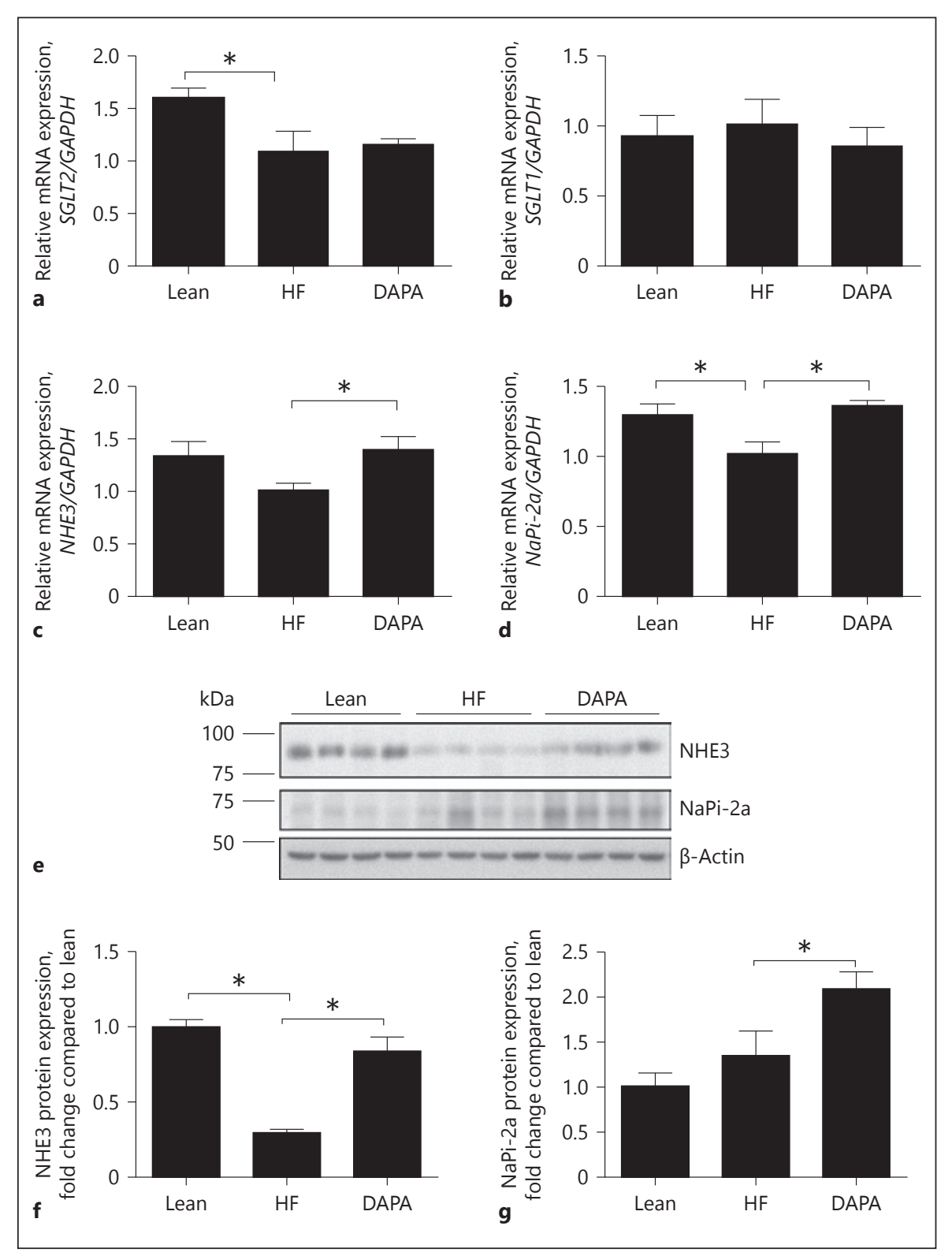

when compared with vehicle-control mice $(p<0.05)$ (Fig. 4a). In addition, the expression of $\mathrm{ENaC} \beta$ and $\mathrm{ENaC} \gamma$ declined significantly by 13 and $26 \%$, respectively, in the dapagliflozin-treated group compared to vehiclecontrols ( $p<0.05$ each; Fig. 4b, c).

\section{The Effect of Dapagliflozin on Expression of}

$\mathrm{Na}^{+}-\mathrm{K}^{+}$-ATPase and Glucose Transporters

We also evaluated the effect of dapagliflozin on glucose transporter 2 (Glut2) and $\mathrm{Na}^{+}-\mathrm{K}^{+}$-ATPase transporters by RT-qPCR. The expression of Atp1b1 was significantly increased by $32 \%$ in the dapagliflozin-treated mice compared to that of the vehicle-control group ( $p<$ 0.05 ; Fig. $5 \mathrm{~b}$ ). The expression of Atp 1a1 was not changed in the dapagliflozin-treated group $(p>0.2)$. Dapagliflozin treatment caused a slight reduction in the expression of Glut2 compared to the vehicle-control group, but this effect failed to reach statistical significance ( $p=0.08$; Fig. $5 \mathrm{a}, \mathrm{c}$ ). Western blot analysis was further used to investigate the protein expression level of ATP1b1 (Fig. 5d). ATP1b1 expression was increased by $123 \%$ in the dapagliflozin-treatment group when compared with saline vehicle diabetic mice $(p<0.05$; Fig. 5e). 


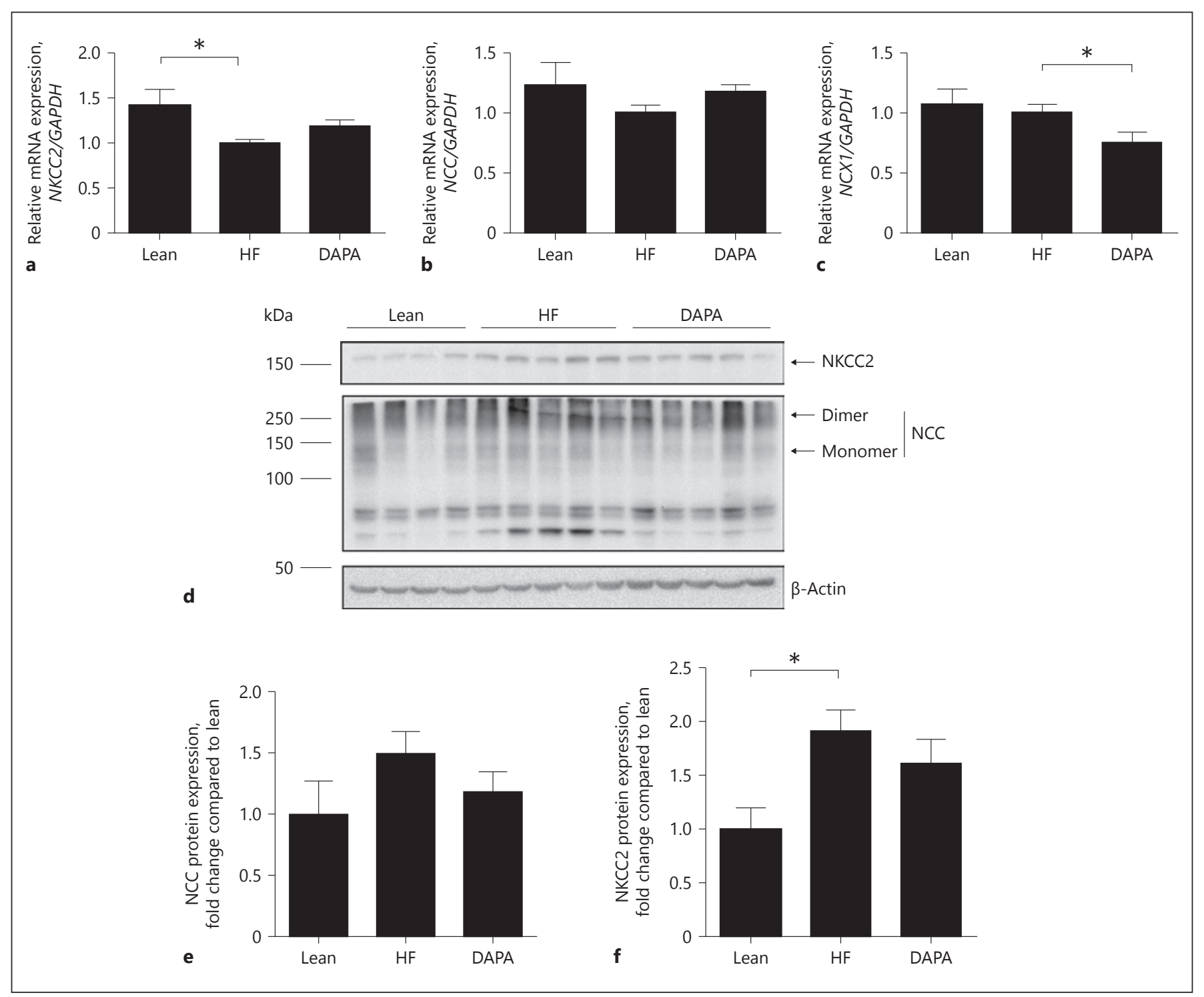

Fig. 3. Effect of dapagliflozin on the expression of the sodium transporters in the loop of Henle. a-c Quantitative RT-PCR analyses for the expression of NKCC2, NCC, and NCX1 in the loop of Henle. d Immunoblot analysis of NKCC2 $(\sim 150 \mathrm{kDa})$, NCC $(\sim 120 \mathrm{kDa})$ in mice fed the indicated diet. e, $\mathbf{f}$ Histograms for

\section{Discussion}

In this study, we demonstrated that the inhibition of SGLT2 increased the mRNA expression level of NHE3, $\mathrm{NaPi}-2 \mathrm{a}$ and $\mathrm{ENaCa}$. Western blotting results show that the protein expression level of NHE3 and NaPi-2a was increased in dapagliflozin-treated mice. Moreover, ATP1b1 protein expression level was also increased. Our findings demonstrate that proximal inhibition of $\mathrm{Na}^{+}$re-
NKCC2, NCC Western blot results and normalized for $\beta$-actin expression. ${ }^{*} p<0.05$. Lean, lean control mice; HF, saline vehicle mice; DAPA, dapagliflozin-treated mice. NKCC2, Na-K-2Cl cotransporter; NCC, Na-Cl cotransporter.

absorption via SGLT2 is compensated by an increased expression of local $\mathrm{Na}^{+}$transporters in the PT but not in the TAL, DCT and CD.

The kidneys reabsorb large amounts of filtered glucose to clear urinary glucose, primarily through the $\mathrm{Na}^{+}$-dependent glucose co-transporter 2 (SGLT2) in the S1 segment of the PT. Inhibitors of SGLT2 are newly developed anti-diabetic agents and interfere with the pathway of physiological glucose reabsorption in the kidney. In this 


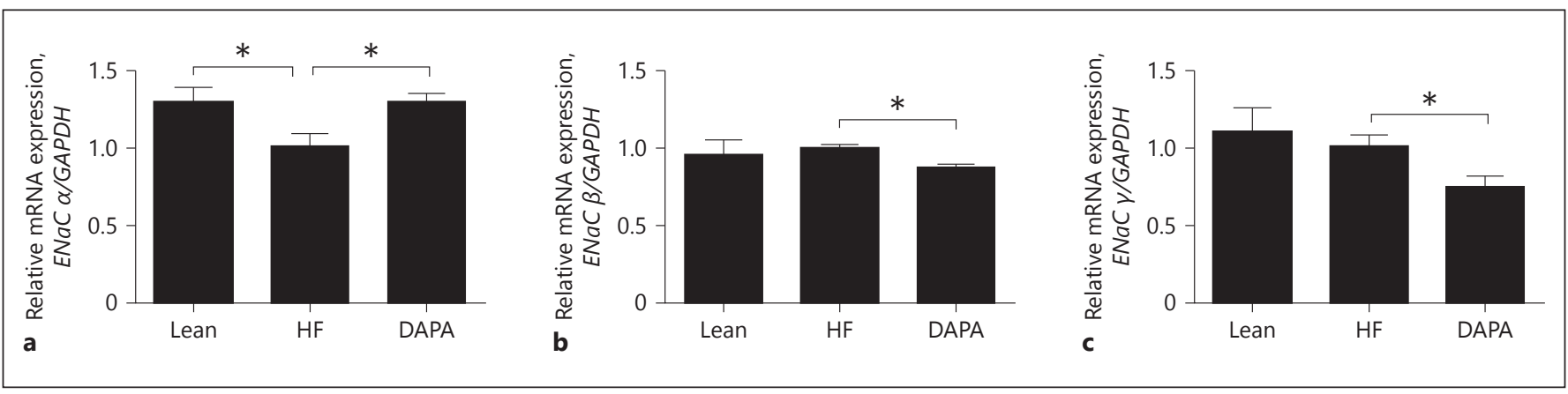

Fig. 4. Effect of dapagliflozin on the expression of the sodium transporters in the DCT. a-c Quantitative RT-PCR analyses for the expression of $E N a C \alpha, E N a C \beta$, and $E N a C \gamma$, in the DCT. ${ }^{*} p<0.05$. Lean, lean control mice; HF, saline vehicle mice; DAPA, dapagliflozintreated mice.

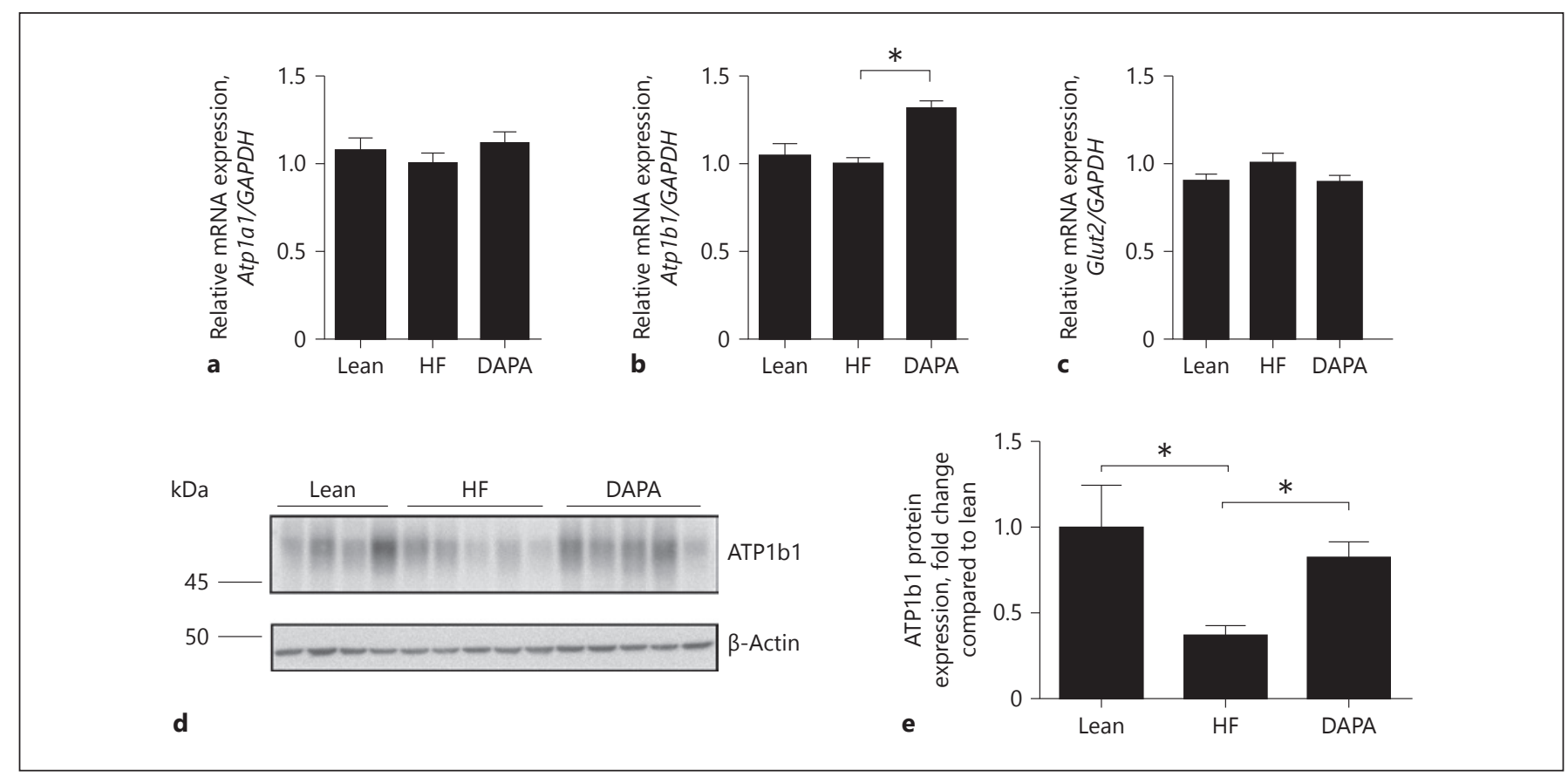

Fig. 5. Effect of dapagliflozin on ATPase and Glut2. a-c Quantitative RT-PCR analyses for the expression of Atp1a1, Atp1b1, and Glut2. d Immunoblot analysis of ATP1b1 $(\sim 50 \mathrm{kDa})$ in mice fed the indicated diet. e Histogram for ATP1b1 Western blot results and normalized for $\beta$-actin expression. ${ }^{*} p<0.05$. Lean, lean control mice; HF, saline vehicle mice; DAPA, dapagliflozin-treated mice. GAPDH, glyceraldehyde 3-phosphate dehydrogenase. study, high fat and STZ induction significantly increased blood glucose when compared with lean group mice. In the dapagliflozin treatment group, we found that blood glucose level decreased significantly when compared with that of the vehicle-control group. In our study, STZ-induced diabetes decreased the SGLT2 expression. Albertoni Borghese et al. [30] have also demonstrated that STZ decreased the SGLT2 expression and activity. In contrast, the SGLT2 expression was increased in Akita/+ mice [31], humans [32] with type 2 diabetes, and alloxan-induced diabetic rats [33]. Indeed, the use of different diabetic models may, therefore, result in different SGLT2 expression. However, despite lower SGLT2 expression in STZinduced mice, dapagliflozin treatment reduced blood glucose levels. We therefore expect that in other studies with higher SGLT2 expression, the observed effects may even be larger. Moreover, dapagliflozin treatment did not change SGLT2 expression in our experiment. The expres- 
sion of SGLT2 does not necessarily alter upon dapagliflozin treatment. Other studies also found that pharmacological SGLT2 inhibition does not affect the expression of SGLT2 [31, 34]. Given the reduction of blood glucose concentrations in the dapagliflozin-treated group at day 18 when compared with saline vehicle mice, the lowered SGLT2 expression did not impair the effects of dapagliflozin treatment. Therefore, we do not expect that this has a major impact on our results.

SGLT2 inhibitors improve glucose control by inducing glycosuria, but they also reduce the reabsorption of $\mathrm{Na}^{+}$. Inhibition of $\mathrm{Na}^{+}$reabsorption in the PT will switch on compensatory systems in more distally located segments to counteract the proximal $\mathrm{Na}^{+}$loss. A recent study has shown that dapagliflozin treatment upregulated the expression of urea transporter-A1, aquaporin-2, and NKCC2 proteins [1]. However, little is known about the effects of SGLT2 inhibitors on the local and downstream $\mathrm{Na}^{+}$transporters. We investigated how proximal $\mathrm{Na}^{+}$ wasting affects local and downstream $\mathrm{Na}^{+}$transporters/ channels' expression in high-fat diabetic mice.

The management of hypertension in diabetes is not without controversy [17]. Hence, the precise level at which anti-hypertensive therapy should be initiated and what the target blood pressure should be remain difficult issues. Many patients with type 2 diabetes receive multiple drugs to treat both hyperglycaemia and hypertension. The new class of SGLT2 inhibitors also induces renal $\mathrm{Na}^{+}$ wasting and, therefore, will have blood pressure-reducing properties. However, some studies report an impressive diuretic effect and consequent reduction in blood pressure, while others described modest effects on volume status $[17,35]$. It is known that the compensatory capacity of the kidney is immense [36]. The inhibition of $\mathrm{Na}^{+}$ reabsorption in the PT will turn on compensatory systems in local or more distally located segments to counteract the proximal $\mathrm{Na}^{+}$loss.

In this study, dapagliflozin treatment significantly increased the mRNA expression level of NHE3, NaPi-2a and ENaCa. In line with the mRNA expression level, Western blot results showed that NHE3, NaPi-2a also increased in the dapagliflozin treatment group when compared to that in saline vehicle mice. Therefore, our results suggest that the inhibition of $\mathrm{Na}^{+}$-glucose transporter 2 in the PT can turn on the local and downstream $\mathrm{Na}^{+}$compensatory systems. Increased reabsorption of $\mathrm{Na}^{+}$may elevate blood pressure in the type 2 diabetes [37-39]. Wang et al. [38] showed that a changed expression of $\mathrm{Na}^{+}$transport in renal PT can be compensated by changes in more distal tubule in nephron, tubuloglomerular feedback and also by glomerular filtration rate adjustments. Nevertheless, extracellular fluid volume and consequently blood pressure can also be affected by the changed expression of sodium transport in PT. Sodium reabsorption initially happens at the PT apical membrane, therefore resulting in making apical sodium transport critical in adjusting the extracellular fluid volume and ultimately blood pressure control. Indeed, in polygenic human essential hypertension, the increase in sodium transport occurs at the PT and TAL of Henle [40-42] rather than in more distal nephron segments that is characteristic of monogenic hypertension [43]. Unfortunately, there were no plasma and urine electrolytes results in this study. Therefore, further studies are needed to better understand of the compensatory mechanisms of $\mathrm{Na}^{+}$transporters distal from the PT to adjust blood pressure control.

SGLT2 is located in the S1 segment and accounts for $90 \%$ of the glucose reabsorption from the kidneys [4447]. $\mathrm{Na}^{+}$absorption across the cell membrane creates an energy gradient that in turn allows the absorption of glucose. On the other side of the cell, $\mathrm{Na}^{+}$is extruded through $\mathrm{Na}^{+}-\mathrm{K}^{+}$-ATPase into the bloodstream [48-50]. The concentration gradient within the cell, resulting from this exchange drives glucose reabsorption into the bloodstream via GLUT2 [51-53]. In order to evaluate if the increased expression of $\mathrm{Na}^{+}$transporters in the $\mathrm{PT}$ and $\mathrm{CD}$ influenced the expression of $\mathrm{Na}^{+}-\mathrm{K}^{+}$-ATPase and GLUT2, we furthermore tested the expression of Atp1a1 and Atp1b1 and Glut 2 transporters by RT-qPCR. The results revealed that the expression of Atp1b1 increased significantly in the dapagliflozin-treated group; however, the expression of Atp1a1 and Glut2 did not change. Furthermore, ATP1b1 protein expression level was also increased in the dapagliflozin-treated group. The increased expression of ATP1b1 may facilitate $\mathrm{Na}^{+}$to be transported into the bloodstream, which could lead to salt retention and hypertension. These effects may blunt the potential BP-lowering effects of the SGLT2 inhibitor. This is also a risk for the type 2 diabetes patients to have hypertension [54].

In conclusion, we demonstrated that the SGLT2 inhibitor, dapagliflozin, increased the expression of NHE3, NaPi-2a in the PT. Furthermore, ATP1b1 was also upregulated, which may facilitate the uptake of the $\mathrm{Na}^{+}$into the blood.

\section{Acknowledgement}

This work was supported by grants from the Radboud Institute for Molecular Life Sciences (to Joost Hoenderop and Bastiaan de Galan).
Ma/de Baaij/Millar/Gault/de Galan/ Bindels/Hoenderop 


\section{Ethics Statement}

The authors have no ethical conflicts to disclose.

\section{Disclosure Statement}

The authors declare that they have no conflicts of interest to disclose.

\section{Author Contributions}

C.M., J.H.F.B., R.J.M.B., B.E.G., and J.G.J.H. designed the study; C.M. and P.J.M. performed experiments; C.M., J.H.F.B., P.J.M., V.A.G., R.J.M.B., B.E.G., and J.G.J.H. analyzed and interpreted data; C.M., J.H.F.B., P.J.M., V.A.G., R.J.M.B., and J.G.J.H. wrote the manuscript. J.H.F.B., B.E.G., R.J.M.B., and J.G.J.H. supervised the study; and all authors approved of the final manuscript.

\section{References}

1 Chen L, LaRocque LM, Efe O, Wang J, Sands JM, Klein JD. Effect of Dapagliflozin Treatment on Fluid and Electrolyte Balance in Diabetic Rats. Am J Med Sci. 2016 Nov;352(5):517-23.

2 Shi Y, Hu FB. The global implications of diabetes and cancer. Lancet. 2014 Jun;383(9933): $1947-8$.

3 Vos T, Flaxman AD, Naghavi M, Lozano R, Michaud C, Ezzati M, et al. Years lived with disability (YLDs) for 1160 sequelae of 289 diseases and injuries 1990-2010: a systematic analysis for the Global Burden of Disease Study 2010. Lancet. 2012 Dec;380(9859):2163-96.

4 Death rates fall for 8 of 10 top causes; Alzheimer's up to no. 6. Hosp Health Netw. 2008 Jul;82(7):127.

5 Campbell NR, Gilbert RE, Leiter LA, Larochelle P, Tobe S, Chockalingam A, Ward R, Morris D, Tsuyuki RT, Harris SB. Hypertension in people with type 2 diabetes: Update on pharmacologic management. Can Fam Physician. 2011 Sep;57(9):997-1002.

6 Cheung BM, Li C. Diabetes and hypertension: is there a common metabolic pathway? Curr Atheroscler Rep. 2012 Apr;14(2):160-6.

7 Canale MP, Manca di Villahermosa S, Martino G, Rovella V, Noce A, De Lorenzo A, et al. Obesity-related metabolic syndrome: mechanisms of sympathetic overactivity. Int J Endocrinol. 2013;2013:865965.

8 Oliva RV, Bakris GL. Blood pressure effects of sodium-glucose co-transport2 (SGLT2) inhibitors. J Am Soc Hypertens. 2014 May;8(5):330-9.

9 Gorboulev V, Schürmann A, Vallon V, Kipp $\mathrm{H}$, Jaschke A, Klessen $\mathrm{D}$, et al. $\mathrm{Na}(+)$-D-glucose cotransporter SGLT1 is pivotal for intestinal glucose absorption and glucose-dependent incretin secretion. Diabetes. 2012 Jan; 61(1):187-96

10 Vrhovac I, Balen Eror D, Klessen D, Burger C, Breljak D, Kraus $\mathrm{O}$, et al. Localizations of $\mathrm{Na}(+)$-D-glucose cotransporters SGLT1 and SGLT2 in human kidney and of SGLT1 in human small intestine, liver, lung, and heart. Pflugers Arch. 2015 Sep;467(9):1881-98.

11 Wright EM, Loo DD, Hirayama BA. Biology of human sodium glucose transporters. Physiol Rev. 2011 Apr;91(2):733-94.

12 Plosker GL. Dapagliflozin: a review of its use in type 2 diabetes mellitus. Drugs. 2012 Dec; 72(17):2289-312.
13 Ptaszynska A, Johnsson KM, Parikh SJ, de Bruin TW, Apanovitch AM, List JF. Safety profile of dapagliflozin for type 2 diabetes: pooled analysis of clinical studies for overall safety and rare events. Drug Saf. 2014 Oct; 37(10):815-29.

14 Wilding JP, Woo V, Rohwedder K, Sugg J, Parikh S; Dapagliflozin 006 Study Group. Dapagliflozin in patients with type 2 diabetes receiving high doses of insulin: efficacy and safety over 2 years. Diabetes Obes Metab. 2014 Feb;16(2):124-36.

$15 \mathrm{Kaku} \mathrm{K}$, Inoue S, Matsuoka O, Kiyosue A, Azuma H, Hayashi N, et al. Efficacy and safety of dapagliflozin as a monotherapy for type 2 diabetes mellitus in Japanese patients with inadequate glycaemic control: a phase II multicentre, randomized, double-blind, placebocontrolled trial. Diabetes Obes Metab. 2013 May;15(5):432-40.

16 Ferrannini E, Ramos SJ, Salsali A, Tang W, List JF. Dapagliflozin monotherapy in type 2 diabetic patients with inadequate glycemic control by diet and exercise: a randomized, double-blind, placebo-controlled, phase 3 trial. Diabetes Care. 2010 Oct;33(10):2217-24.

17 Lovshin JA, Gilbert RE. Are SGLT2 inhibitors reasonable antihypertensive drugs and renoprotective? Curr Hypertens Rep. 2015 Jun; 17(6):551.

18 Wright JT Jr, Williamson JD, Whelton PK, Snyder JK, Sink KM, Rocco MV, et al.; SPRINT Research Group. A Randomized Trial of Intensive versus Standard Blood-Pressure Control. N Engl J Med. 2015 Nov; 373(22):2103-16.

19 Kohan DE, Fioretto P, Tang W, List JF. Longterm study of patients with type 2 diabetes and moderate renal impairment shows that dapagliflozin reduces weight and blood pressure but does not improve glycemic control. Kidney Int. 2014 Apr;85(4):962-71.

20 Osorio H, Bautista R, Rios A, Franco M, Santamaría J, Escalante B. Effect of treatment with losartan on salt sensitivity and SGLT2 expression in hypertensive diabetic rats. Diabetes Res Clin Pract. 2009 Dec;86(3):e46-9.

21 Vallon V, Thomson SC. Renal function in diabetic disease models: the tubular system in the pathophysiology of the diabetic kidney. Annu Rev Physiol. 2012;74(1):351-75.
22 Fujimoto M, Naito K, Kubota T. Electrochemical profile for ion transport across the membrane of proximal tubular cells. Membr Biochem. 1980;3(1-2):67-97.

23 Cadnapaphornchai MA, Kim YW, Gurevich AK, Summer SN, Falk S, Thurman JM, et al. Urinary concentrating defect in hypothyroid rats: role of sodium, potassium, 2-chloride cotransporter, and aquaporins. J Am Soc Nephrol. 2003 Mar;14(3):566-74.

24 Palmer LG, Frindt G. Amiloride-sensitive Na channels from the apical membrane of the rat cortical collecting tubule. Proc Natl Acad Sci USA. 1986 Apr;83(8):2767-70.

25 van der Wijst J, Tutakhel OA, Bos C, Danser AH, Hoorn EJ, Hoenderop JG, et al. Effects of a high-sodium/low-potassium diet on renal calcium, magnesium, and phosphate handling. Am J Physiol Renal Physiol. 2018 Jul; 315(1):F110-22.

26 Custer M, Lötscher M, Biber J, Murer H, Kaissling B. Expression of Na-P(i) cotransport in rat kidney: localization by RT-PCR and immunohistochemistry. Am J Physiol. 1994 May;266(5 Pt 2):F767-74.

27 de Groot T, Sinke AP, Kortenoeven ML, Alsady M, Baumgarten R, Devuyst O, et al. Acetazolamide Attenuates Lithium-Induced Nephrogenic Diabetes Insipidus. J Am Soc Nephrol. 2016 Jul;27(7):2082-91.

28 GottardiCJ, Caplan MJ. Delivery of $\mathrm{Na}+, \mathrm{K}(+)-$ ATPase in polarized epithelial cells. Science. 1993 Apr;260(5107):552-4.

29 de Baaij JH, Kompatscher A, Viering DH, Bos C, Bindels RJ, Hoenderop JG. P2X6 Knockout Mice Exhibit Normal Electrolyte Homeostasis. PLoS One. 2016 Jun;11(6): e0156803.

30 Albertoni Borghese MF, Majowicz MP, Ortiz MC, Passalacqua MR, Sterin Speziale NB, Vidal NA. Expression and activity of SGLT2 in diabetes induced by streptozotocin: relationship with the lipid environment. Nephron, Physiol. 2009;112(3):45-52.

31 Vallon V, Gerasimova M, Rose MA, Masuda T, Satriano J, Mayoux E, et al. SGLT2 inhibitor empagliflozin reduces renal growth and albuminuria in proportion to hyperglycemia and prevents glomerular hyperfiltration in diabetic Akita mice. Am J Physiol Renal Physiol. 2014 Jan;306(2):F194-204. 
32 Quinn PG, Yeagley D. Insulin regulation of PEPCK gene expression: a model for rapid and reversible modulation. Curr Drug Targets Immune Endocr Metabol Disord. 2005 Dec;5(4):423-37.

33 Freitas HS, Anhê GF, Melo KF, Okamoto MM, Oliveira-Souza M, Bordin S, et al. $\mathrm{Na}(+)$ -glucose transporter-2 messenger ribonucleic acid expression in kidney of diabetic rats correlates with glycemic levels: involvement of hepatocyte nuclear factor-1alpha expression and activity. Endocrinology. 2008 Feb;149(2): 717-24.

34 Gembardt F, Bartaun C, Jarzebska N, Mayoux E, Todorov VT, Hohenstein B, et al. The SGLT2 inhibitor empagliflozin ameliorates early features of diabetic nephropathy in BTBR ob/ob type 2 diabetic mice with and without hypertension. Am J Physiol Renal Physiol. 2014 Aug;307(3):F317-25.

35 List JF, Woo V, Morales E, Tang W, Fiedorek FT. Sodium-glucose cotransport inhibition with dapagliflozin in type 2 diabetes. Diabetes Care. 2009 Apr;32(4):650-7.

36 Roth KS. Diagnosis of renal tubular transport disorders. A guide for the clinician. Clin Pediatr (Phila). 1988 Oct;27(10):463-70.

37 Pratt JH. Central role for ENaC in development of hypertension. J Am Soc Nephrol. 2005 Nov;16(11):3154-9.

38 Wang X, Armando I, Upadhyay K, Pascua A, Jose PA. The regulation of proximal tubular salt transport in hypertension: an update. Curr Opin Nephrol Hypertens. 2009 Sep; 18(5):412-20.
39 Xu L, Dixit MP, Chen R, Dixit NM, Collins JF, Ghishan FK. Effects of angiotensin II on NaPi-IIa co-transporter expression and activity in rat renal cortex. Biochim Biophys Acta. 2004 Dec;1667(2):114-21.

40 Doris PA. Renal proximal tubule sodium transport and genetic mechanisms of essential hypertension. J Hypertens. 2000 May; 18(5):509-19.

41 Ortiz PA, Garvin JL. Intrarenal transport and vasoactive substances in hypertension. Hypertension. 2001 Sep;38(3 Pt 2):621-4.

42 Staessen JA, Kuznetsova T, Zhang H, Maillard M, Bochud M, Hasenkamp S, et al. Blood pressure and renal sodium handling in relation to genetic variation in the DRD1 promoter and GRK4. Hypertension. 2008 Jun;51(6):1643-50.

43 Ji W, Foo JN, O’Roak BJ, Zhao H, Larson MG, Simon DB, et al. Rare independent mutations in renal salt handling genes contribute to blood pressure variation. Nat Genet. 2008 May;40(5):592-9.

44 Fujita Y, Inagaki N. Renal sodium glucose cotransporter 2 inhibitors as a novel therapeutic approach to treatment of type 2 diabetes: clinical data and mechanism of action. J Diabetes Investig. $2014 \mathrm{May} ; 5(3): 265-75$.

45 Santer R, Calado J. Familial renal glucosuria and SGLT2: from a mendelian trait to a therapeutic target. Clin J Am Soc Nephrol. 2010 Jan;5(1):133-41.

46 Kanai Y, Lee WS, You G, Brown D, Hediger MA. The human kidney low affinity $\mathrm{Na}+/$ glucose cotransporter SGLT2. Delineation of the major renal reabsorptive mechanism for $\mathrm{D}$ - glucose. J Clin Invest. 1994 Jan;93(1):397404.

47 Nomura S. Renal sodium-dependent glucose cotransporter 2 (SGLT2) inhibitors for new anti-diabetic agent. Curr Top Med Chem. 2010;10(4):411-8.

48 Avner ED, Sweeney WE Jr, Finegold DN, Piesco NP, Ellis D. Sodium-potassium ATPase activity mediates cyst formation in metanephric organ culture. Kidney Int. 1985 Sep;28(3):447-55.

49 Ernst SA. Transport ATPase cytochemistry: ultrastructural localization of potassium-dependent and potassium-independent phosphatase activities in rat kidney cortex. J Cell Biol. 1975 Sep;66(3):586-608.

50 Landon EJ, Jazab N, Forte L. Aldosterone and sodium-potassium-dependent ATPase activity of rat kidney membranes. Am J Physiol. 1966 Oct;211(4):1050-6.

51 Poudel RR. Renal glucose handling in diabetes and sodium glucose cotransporter 2 inhibition. Indian J Endocrinol Metab. 2013 Jul; 17(4):588-93.

52 Leloup C, Arluison M, Lepetit N, Cartier N, Marfaing-Jallat P, Ferré P, et al. Glucose transporter 2 (GLUT 2): expression in specific brain nuclei. Brain Res. 1994 Feb;638(1-2):221-6.

53 Thorens B. Molecular and cellular physiology of GLUT-2, a high-Km facilitated diffusion glucose transporter. Int Rev Cytol. 1992;137: 209-38.

54 Ferrannini E, Cushman WC. Diabetes and hypertension: the bad companions. Lancet. 2012 Aug;380(9841):601-10. 